\title{
Poética visceral: feminismo negro, afectos y emociones en la obra de Victoria Santa Cruz
}

\author{
Juan Carlos Zuluaga Díaz*
}

Artículo de reflexión sobre el papel de las emociones en la producción cultural y su influencia en la configuración de feminismos negros e identidades/subjetividades interraciales.

Recibido: 11 de mayo de 2020

Evaluado: 30 de noviembre de 2020

Aceptado: 14 de diciembre de 2020

Publicado: 1 de julio de 2021

Citar como:

Zuluaga, J. C. (2021). Poética visceral: feminismo negro, afectos y emociones en la obra de Victoria Santa Cruz. Hallazgos, 18(36), 291-321.

https://doi.org/10.15332/2422409X.5803

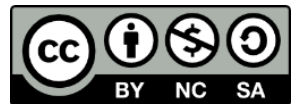

\section{Resumen}

El artículo presenta en primera instancia un panorama del giro afectivo, sus antecedentes, algunas de sus premisas fundamentales y sus principales desarrollos. Posteriormente, se reflexiona en torno a las particularidades del feminismo negro y sus potencialidades para la deconstrucción del sistema patriarcal y el orden social racializado. El núcleo del artículo intenta un análisis fenomenológico de la experiencia y

\footnotetext{
* Magíster en Investigación en Ciencias Sociales (Universidad de Buenos Aires). Profesor del Departamento de Antropología y Sociología de la Universidad de Caldas, Colombia.

Correo electrónico: juanc.zuluaga@ucaldas.edu.co

ORCID: https://orcid.org/0000-0002-8015-3044
}

Hallazgos

ISSN: 1794-3841 | e-ISSN: 2422-409X | DOI: https://doi.org/10.15332/2422409X

Vol. 18 N.o 36| julio-diciembre del 2021 
la obra de la artista afroperuana Victoria Santa Cruz en clave afectiva.

Entre las conclusiones se destaca el importante papel de las emociones

en la construcción y definición de las identidades/subjetividades negras, así como su relación con el sistema de representación colonial y la economía de los afectos. Por otro lado, se devela la importancia de las emociones en los procesos emancipatorios y en la construcción de solidaridades, haciendo de estas una dimensión relevante para la actitud y el activismo político desde la producción cultural.

Palabras clave: Afectos; Afrodescendientes; Discriminación racial; Feminismo; Identidad étnica; Victoria Santa Cruz.

\section{Visceral poetics: black feminism, affections and emotions in the work of Victoria Santa Cruz}

\section{Abstract}

This article first presents an overview of the affective turn, its background, some of its fundamental premises and its main developments. Subsequently, it reflects on the particularities of black feminism and its potential for the deconstruction of the patriarchal system and the racialized social order. The core of the article attempts a phenomenological analysis of the experience and work of the AfroPeruvian artist Victoria Santa Cruz in an affective key. Among the conclusions, it highlights the important role of emotions in the construction and definition of black identities/subjectivities, as well as their relationship with the colonial system of representation and the economy of affections. On the other hand, it reveals the importance of emotions in emancipatory processes and in the construction of solidarities, making them a relevant dimension for attitude and political activism from cultural production.

Keywords: Affections; Afro-descendants; Racial discrimination; Feminism; Ethnic identity; Victoria Santa Cruz. 


\section{Poética visceral: feminismo negro, afetos e emoções na obra de Victoria Santa Cruz}

\section{Resumo}

O artigo apresenta, em primeiro lugar, uma panorama da virada afetiva, seus antecedentes, algumas de suas premissas fundamentais e seus principais desdobramentos. Posteriormente, reflete sobre as particularidades do feminismo negro e seu potencial para a desconstrução do sistema patriarcal e da ordem social racializada. $\mathrm{O}$ núcleo do artigo busca uma análise fenomenológica da experiência e da obra da artista afro-peruana Victoria Santa Cruz de forma afetiva. Entre as conclusões, destaca-se o importante papel das emoções na construção e definição das identidades/subjetividades negras, bem como sua relação com o sistema de representação colonial e a economia dos afetos. Por outro lado, revela-se a importância das emoções nos processos emancipatórios e na construção de solidariedades, tornando-as uma dimensão relevante para a atitude e o ativismo político a partir da produção cultural.

Palavras-chave: Afetos; Afro-descendentes; Discriminação racial; Feminismo; Identidade étnica; Victoria Santa Cruz.

\section{Introducción}

En 2010, mientras oficiaba como coordinador general de un proyecto concertado entre Unifem y la fundación Akina Zaji Sauda sobre prevención y atención de las violencias sobre las mujeres negras del municipio de Buenaventura, Colombia, conocí por intermedio de una colega parte de la obra de la artista afroperuana Victoria Santa Cruz. De inmediato me impactó la fuerza de carácter, la seriedad y la apuesta personal de la autora frente la identidad afro, la cuestión racial y el orden patriarcal, temas sobre los cuales giró incansablemente su producción artística. 
Ahora bien, por la actualidad epistémica de su obra, en primera instancia creí que se trataba de una artista que podría inscribirse en lo que se conoce como la tercera ola feminista, pues su obra, además de la postura antirracista, contiene a todas luces elementos que podrían rastrearse en corrientes de las ciencias sociales relacionadas con el posestructuralismo, como el carácter performativo del lenguaje (Wittgenstein, Foucault, Derrida, Butler, entre otros) y la elevación del sujeto a categoría analítica, así como presupuestos decoloniales/poscoloniales en relación con las “opresiones múltiples" (Lugones), la voz del subalterno (Spivak) y la deconstrucción de los mecanismos y las representaciones de la colonialidad (Fanon), entre otros. Sin embargo, estamos hablando de una artista que ha sido vinculada, junto con la poeta cubana Nancy Morejón, al protofeminismo negro latinoamericano de mediados del siglo XX, cuando los desarrollos académicos antes mencionados apenas estaban en ciernes o poco instalados en el imaginario latinoamericano.

El poema "Me gritaron negra" de Victoria Santa Cruz ha sido analizado por autores-tanto mujeres como hombres-desde distintas perspectivas, desde el análisis de contenido del subtexto jurídico (Gordillo, 2020) hasta el análisis discursivo (Maiarú, 2018), pasando por estudios literarios asociados con el feminismo negro (Nieto, 2019). No obstante, a la fecha no se conocen reflexiones en las que el centro de atención sea el papel de los afectos en la obra de Santa Cruz, la potencia de las emociones, su relación con el contexto histórico de producción y con la construcción de las subjetividades subalternas. Esto constituye parte de la originalidad de la reflexión propuesta en este artículo.

Partiendo de la experiencia de infancia narrada por la autora -que constituye el locus del poema "Me gritaron negra" - y el desarrollo enunciativo de su prosa, se pretende realizar un análisis fenomenológico en clave afectiva, específicamente siguiendo la perspectiva de Sara Ahmed 
(2015). En tal sentido, el proceder metodológico tuvo como base la lectura crítica de la obra, con el fin de identificar códigos de la estructura del sentimiento desde una postura de experiencia vicaria del sujeto cognoscente (Pujadas, 2002), en relación con el contexto históricoideológico en el que se inscribe la autora.

El artículo presenta en primera instancia un panorama del giro afectivo, sus antecedentes, algunas de sus premisas fundamentales y principales desarrollos. Posteriormente, se reflexiona en torno a algunas particularidades del feminismo negro y sus potencialidades para la deconstrucción del sistema patriarcal y el orden social racializado, seguido de una breve semblanza de Victoria Santa Cruz y la presentación de su poema "Me gritaron negra". La segunda parte del documento constituye el núcleo de la reflexión, en la cual se procura analizar un vínculo histórico de producción de la obra en relación con lo que Roberto Retamar señala como elementos políticos en lo poético, capaces de motivar transformaciones revolucionarias, sumando elementos conceptuales del pensamiento decolonial y, principalmente, del denominado "giro afectivo".

\section{El giro afectivo: antecedentes y presupuestos}

Las últimas décadas han visto el despertar de los afectos en el escenario académico, político, cultural y el activismo de género. Si bien en el ámbito de la filosofía política la cuestión de las pasiones tuvo un lugar importante en la discusión sobre la modernidad y el Estado moderno (Spinoza, Smith, Hobbes, Rousseau), y en el campo sociológico los padres fundadores de dicha disciplina reconocieron, en ocasiones subrepticiamente, la influencia de las emociones en la vida social (Illouz, 2007), existe cierto consenso sobre la idea de que las emociones se perdieron con el ingreso a la modernidad, en la medida en que esta supone un proceso de racionalización, que viene desde el siglo XVI. Autores como Elias y

Hallazgos

ISSN: 1794-3841 | e-ISSN: 2422-409X | DOI: https://doi.org/10.15332/2422409X 
Huizinga comparten presupuestos según los cuales el paso de la Edad Media a la moderna significó la pérdida de la manifestación espontánea y descontrolada de las emociones, lo que dio paso a la contención, la racionalización y la psicologización de estas, así como de las instancias instintivas. Esto ha generado lo que se conoce como la autoconciencia de Occidente (Macón y Solana, 2015). No obstante, recientes indagaciones desde diferentes perspectivas y campos de estudio dan cuenta del papel de las emociones y de una "cultura emocional" en la construcción y en el desarrollo del capitalismo (Nussbaum, 2008; Mouffe, 2016; Butler, 2002; Illouz, 2007; Massumi, 2002; Flatley, 2008; Cvetkovich, 2012; Ahmed, 2015).

El interés actual por los aspectos emocionales responde, según Ahmed (2015), a la preminencia de "regímenes de sentimentalidad" en casi todas las dimensiones de lo social, desde la justicia y la política hasta los medios de comunicación y los negocios. Este clima emocional de las sociedades globalizadas constituye el contexto en el que se instalan discusiones epistemológicas dentro de la ciencias sociales y las humanidades en la segunda mitad del siglo XX, en las que la corriente posestructuralista y el denominado "giro lingüístico" empezaron a llamar la atención sobre cómo tecnologías y dispositivos discursivos producen la realidad social y coadyuvan a configurar el ámbito de las subjetividades modernas. Esto, puede decirse, abre la puerta epistémica para la exploración de las emociones como elementos articuladores que exceden la dimensión exclusivamente discursiva, sin llegar a desestimarla.

En un sentido amplio, el "giro afectivo" no busca invalidar el posestructuralismo "sino llevar algunas de sus premisas al terreno de lo corporal” (Macón y Solana, 2015, p. 12). Así, de la mano del posestructuralismo (Deleuze, Foucault, Derrida) y de la teoría queer, aunque no siempre en concordancia plena, emergen novedosas 
indagaciones desde distintas disciplinas (sociología, antropología, estudios literarios y de comunicación), las cuales tienen por objeto de estudio el papel de las emociones, su función y su uso político en procesos de dominación y emancipación.

El llamado "giro afectivo" surge en los años noventa en medio de reflexiones y controversias en el marco de las teorías de género, si bien sus antecedentes inmediatos lo vinculan con algunos trabajos de la sociología de las emociones (Zelizer, Lutz, Hochschild, Illouz). Según Macón (2013), se pueden detectar antecedentes inmediatos del giro hacia los años ochenta, relacionándolo con la corriente feminista del cuidado, específicamente con algunos de sus presupuestos, como la idea de que las mujeres estarían más abiertas que los varones a la manifestación de las emociones y que "establecen sus vínculos morales basadas en la lógica del cuidado" (p. 5). En este marco conceptual el cuidado es visto positivamente en la medida en que implica una forma de pensar de carácter narrativo, en la que destaca su cercanía con las necesidades del otro y la preocupación por el detalle. De este modo, el cuidado implicaría decididamente los afectos y la (re)producción de aquello que Raymond Williams llamaría "estructuras del sentimiento".

Por otro lado, se destacan los aportes de Nussbaum (2008) al giro afectivo, en especial su original reflexión teórica sobre el papel de las emociones en un campo como el de la justicia, tradicionalmente ligado a la más estricta racionalidad. Así mismo, productos intelectuales de autoras feministas como Chantal Mouffe (2016) e Iris M. Young (2000) desarrollaron ideas centrales en torno a las relaciones políticas, la democracia liberal y las emociones, superponiendo estas últimas a las estrategias racionales, en la medida en que son consideradas mucho más genuinas y cercanas a la naturaleza humana. 
La perspectiva denominada como "giro afectivo" no es per se un campo homogéneo y plenamente consensuado. Siguiendo a Macón y Solana (2015), se pueden diferenciar dos tendencias en el movimiento: una orientación, cuyo principal exponente es Brian Massumi (2002), que entiende el campo afectivo como potencialmente emancipatorio, dada su capacidad para transformar la experiencia y promover la praxis revolucionaria (aunque también para desactivarla). La segunda tendencia, denominada crítica, se deslinda de la anterior por considerarla una mirada algo romantizada de las emociones. Sus principales exponentes (Laurent Berlanty Sara Ahmed) pretenden desarrollar una teoría estructural de las emociones que permita explicar su circuito reproductivo, preguntándose cómo se generan, reproducen y distribuyen a través de la economía de los afectos. En esta "economía" las emociones están jerarquizadas y son jerarquizantes, pues al tiempo que son clasificadas (positivas/negativas; altas/bajas) constituyen herramientas de clasificación al instalarse como atributos individuales/colectivos de los cuerpos o de las cosas (Ahmed, 2015). De tal forma, para la perspectiva crítica existe una política cultural (económica) de las emociones, a través de la cual se crea y reproduce la idea de otredad mediante el agrupamiento de algunos cuerpos y la marginación de otros.

Los afectos en la perspectiva de la mayor parte de las integrantes del giro afectivo son considerados como parte del orden de la materialidad. Tienen efectivamente un carácter performativo cuando son capaces de "alterar con su irrupción la esfera pública” (Macón y Solana, 2015, p. 18). Adquieren igualmente materialidad cuando se les considera, a la manera de Illouz (2007), como la energía interna que nos impulsa a actuar. Es decir, son parte constitutiva de la acción, su potencia. En el mismo sentido, Ahmed (2015) entiende que existe un vínculo indeterminado entre emociones y acción/inacción, en el que las primeras se entienden no como 
estados psicológicos, sino como la fuerza que impulsa a las personas a actuar o a permanecer inmóviles.

Sara Ahmed, como buena parte de los miembros del giro, pretende romper con la concepción binaria que opone la emoción a la razón (Kant). Esta concepción dicotómica presenta a las emociones como irrelevantes para la justicia e insensatas para el discernimiento, estableciendo jerarquías entre las personas y/o grupos, procurando con esto que algunos sean vistos como menos morales o menos capaces de realizar juicios, hasta llegar a señalarlos como seres que se "dejan llevar por las emociones”. Este modelo ético no solo va en contra de la realidad sino que "justifica la 'injusticia' como signo del imperio de la ley" (Ahmed, 2015, p. 294), pues, aun cuando se pretenda ocultar, el proceso de realización de un juicio hacia otro está mediado inexorablemente por una política cultural de las emociones (Young, 2000), haciendo que los cuerpos adquieran de manera diferencial un determinado valor. De tal forma, teniendo unos cuerpos mayor valor que otros, la desigualdad entre estos es inevitable. Es así como la emoción diferencia y puede legitimar, generar o aceptar la desigualdad.

En los distintos dispositivos y tecnologías de dominación de la sociedad capitalista, las emociones desempeñan un papel central, en la medida en que pueden configurar, reproducir, acentuar o justificar las desigualdades a través de vectores de discriminación, tales como el sexismo, la homofobia o el racismo (los cuales actúan interseccionalmente). Este último, que es el eje central de la reflexión propuesta en este artículo, es sin duda un subproducto de la sociedad moderna occidental, incluido a su vez en una política cultural de las emociones que resulta organizada, entre otras normatividades, alrededor de una moral racial que distribuye atributos, clasifica y jerarquiza a las personas según sus rasgos fenotípicos. 


\section{Orden racial y feminismos negros}

Según Restrepo (2003), la discriminación es un acto de diferenciación y un ejercicio de exclusión. Se considera un acto de diferenciación en la medida en que supone la clasificación de una persona o grupo, diferenciándola de otra persona u otros grupos a partir de un conjunto de imágenes y concepciones prexistentes en una configuración social y en quien ejerce la discriminación. La otra dimensión de la discriminación es la exclusión, que puede incluir la segregación, el rechazo, la desvalorización, la negación de oportunidades o el desconocimiento de quien es objeto de discriminación. Teniendo como base estas características, puede decirse que el racismo es el tipo de discriminación efectuada por las adscripciones raciales atribuidas a una persona o colectividad.

La estructura social en América se ha construido sobre la base de un orden sociocultural heredado de una forma de organización colonial, cuyos ejes de poder están fuertemente anclados en la relación capital-trabajo y en la noción de raza como justificante de la dominación y explotación del hombre blanco europeo sobre las poblaciones indígenas y afrodescendientes (Lander, citado en Zuluaga, 2015, p. 312).

Desde la perspectiva decolonial, la raza es considerada una categoría social y mental de la modernidad. Inscrita originariamente en las diferencias fenotípicas entre conquistadores y conquistados, pronto tuvo como referencia supuestas estructuras biológicas diferenciales entre unos y otros, constituyendo en América relaciones sociales fundadas en la idea de una "natural" superioridad racial del hombre blanco europeo. Para el grupo de investigación modernidad/colonialidad, el conjunto de estas relaciones produce en América nuevas identidades sociales, tales como mestizos, indios, negros y un sinnúmero de gradaciones jerárquicoraciales, las cuales fueron asociadas a unos papeles y lugares impuestos desde el orden y la mirada colonial de los dominantes. De tal forma, raza e 
identidad racial fueron establecidas como instrumentos de clasificación social y dominación de la población, en los que los rasgos físicos, así como los productos materiales y culturales de las personas indígenas, y más aún los de las personas negras, fueron situados en una posición de inferioridad que los hizo deleznables (Zuluaga, 2015, p. 312).

Buena parte de las injusticias históricas sufridas por las víctimas de discriminación racial están ampliamente documentadas. Así mismo, las desventajas acumuladas que encaran las mujeres frente a los hombres en la mayor parte del mundo son una realidad innegable. Ahora bien, cuando el hecho de ser mujer se articula con la cuestión racial y de clase se hace evidente una doble/triple discriminación, llamada también discriminación interseccional, la cual repercute en asimetrías tanto en las condiciones materiales de vida de quienes la padecen como en los aspectos emocionales, simbólicos y de prestigio social.

Si bien el cuestionamiento a la supremacía masculina por parte de las mujeres tiene antecedentes históricos de larga data (siglo XIII), la lucha de la mujer comienza a tener finalidades precisas a partir de la Revolución francesa, ligada a la búsqueda de igualdad de derechos políticos, civiles, laborales y educativos; pero es recién a mediados del siglo XIX cuando comienza una lucha organizada y colectiva (Gamba, 2008). No obstante, dentro de las mismas luchas feministas se presentan desacuerdos sobre la representación de las mujeres en sentido universal por parte de las mujeres blancas/burguesas, despojando de su propia historia a otros feminismos. En tal sentido, algunas activistas y grupos que no se sienten representados las acusa de aprobar la definición de la opresión, así como del diseño de las estrategias políticas transformadoras (Jabardo, 2012). En palabras de la feminista negra Hooks (2004): 
A menudo las feministas blancas actúan como si las mujeres negras no supiesen que existía la opresión sexista hasta que ellas dieron voz al sentimiento feminista. Creen que han proporcionado a las mujeres negras "el” análisis y "el” programa de liberación. (p. 45)

El reclamo que se hace al feminismo hegemónico es de carácter político, pues se considera un acto de reivindicación de la historia del movimiento feminista negro que ha sido durante mucho tiempo invisibilizado. Autoras como Bell Hooks, Ángela Davis, Audre Lorde, Hazel Carby, Avtar Brah y Patricia Hill Collins fueron las primeras en poner el foco de atención sobre la relación entre la desigualdad de las mujeres negras y la ideología racista, al tiempo que abrieron la puerta a otros feminismos de la diáspora en Europa y Latinoamérica. Estas intelectuales y activistas han hecho importantes aportes a la historia del feminismo y a la comprensión de la experiencia de las mujeres negras en sociedades racialmente diferenciadas, en lo que se ha denominado feminismos poscoloniales, los cuales constituyen perspectivas críticas del propio feminismo hegemónico y de opresiones más específicas.

El movimiento feminista negro nace de la confluencia de dos movimientos del siglo XIX: el abolicionismo y el sufragismo. Según Jabardo (2012), la intersección entre sexismo y racismo fue determinante en la exclusión a las mujeres negras de los dos movimientos, aun cuando tuvieron participación en ambos, principalmente en la lucha contra la esclavitud, pero también estableciendo alianzas temporales con las mujeres blancas en la lucha por el sufragio. De esta época destacan mujeres afroamericanas como Ana Julia Couper, Ida Wells y Sojourner Truth, quienes se adelantaron a su tiempo al detectar la articulación de vectores discriminatorios que posteriormente el feminismo contemporáneo definiría como teoría de la interseccionalidad. 
Las luchas de estas mujeres fueron recogidas y actualizadas a mediados del siglo XX por intelectuales británicas adscritas a la nueva izquierda, que con herramientas teóricas más desarrolladas analizan las condiciones estructurales y las experiencias de las mujeres afro en contextos poscoloniales. Con esto se muestra cierto sentido de continuidad entre el feminismo negro americano y el británico. Se destacan de ese periodo Hazel Carby y Prathiba Parmar, vinculadas con la denominada Escuela de Birmingham. Ellas generaron importantes aportes tanto en la sistematización de las críticas del feminismo negro al feminismo blanco como en las formas de articulación entre racismo y sexismo desde el paradigma de los estudios culturales.

Los feminismos negros latinoamericanos y del Caribe emergen hacia finales del siglo XIX y principios del siglo XX, cuando se devela la participación de las mujeres negras en los movimientos emancipatorios y en la reconstrucción de identidades étnico-raciales de autoafirmación. Sin embargo, solo con los procesos de lucha de liberación nacional y de los movimientos indígenas nacionales y supranacionales de la segunda mitad del siglo XX las subjetividades colonizadas (incluyendo las subjetividades negras) descollan como sujetos de singular importancia en el campo político. Es en este contexto en el que las intelectuales afro empezaron a definir propuestas político-teóricas en relación con diversos temas, como la defensa del territorio, el racismo, las disidencias sexuales, entre otros (González, 2018).

\section{Victoria Santa Cruz}

Victoria Santa Cruz (1922-2014), poeta, compositora y coreógrafa, es considerada una de las pioneras del feminismo negro en Perú y Latinoamérica. Adelantó estudios en la Universidad del Teatro de las Naciones y en la Escuela de Estudios Coreográficos en París. En su país de 
origen ofició como directora del Conjunto Nacional de Folclore del Instituto Nacional de Cultura. Con este grupo realizó gira por Estados Unidos, Canadá, Bélgica, Suiza, Guatemala, El Salvador, Francia, entre otros países. Posteriormente se dedicó a la enseñanza en la Universidad Carnegie Mellon (Francia) hasta 1999. También dirigió talleres en países como Rusia, Dinamarca, Israel, Argentina, España e Italia (Victoria Santa Cruz, 2021).

Victoria Santa Cruz desde sus inicios se preocupó por la inequidad y las desigualdades raciales, así como por los universalismos de la hegemonía feminista blanca. Su posición como artista le permitió conocer parte de Norteamérica, Europa y Latinoamérica, donde se apropió de la historia cultural y la experiencia de la población afro en distintas regiones del mundo. Identificó en cada una de ellas las relaciones asimétricas y el poder racializado que actúa a través de los cuerpos.

Su poema "Me gritaron negra", el cual tomaremos como referente de análisis desde el enfoque afectivo/emocional, es considerado un clásico lírico-poético en el que explora el sentido de lo negro desde su propia experiencia personal. Refleja el choque cultural y el proceso de (re)conocimiento y autoidentificación de una identidad originalmente desgarrada y después reconfigurada, con la potencia de esa dimensión "visceral" que muy bien se expresaba en las primeras etapas del feminismo de finales del siglo XVIII (Macón, 2017).

Me gritaron negra ${ }^{1}$

Preámbulo de la autora:

Voy a contar una historia que está ligada, para los que han escuchado mi poema "Me gritaron negra”. Está ligado a algo que me sucedió cuando,

\footnotetext{
${ }^{1}$ Véase Ingenio Comunicaciones (2008, junio 29).
} 
como digo en mi poema: tenía siete años apenas, cinco años apenas. Así, en La Victoria, donde vivía Sebastián Barranca, las chicas eran todas mestizas, yo era la única negra. Y me acuerdo que en una oportunidad se muda, viene a vivir aquí al barrio una familia muy blanca. La chiquita era gringuita. Y cuando salgo yo a jugar, la gringuita me mira y dice: "Si esa negrita juega, yo me voy". "Bueno", digo yo: "Esta acaba de llegar y ya está poniendo reglas”. Cuál sería mi sorpresa cuando mis amigas me dicen: "Vete, Victoria". Ahhh, una puñalada es una caricia con aquello que me pasó. Yo no sabía que era negra. Cuando digo que yo no sabía que era negra no estoy hablando del color sino de lo que eso implicaba.

Y me retiraron. Y fue muy doloroso. Y nació en mí una cosa de revancha, terrible, porque a partir de ese momento empecé a odiar. A odiar, que si alguien me hubiese puesto una ametralladora iba a matar blancos. Felizmente nadie me la puso. Pero ¿qué pasó?, ¿̇ué pasó? Y por eso repito mi mensaje. Por momentos yo decía (y seguí viviendo y seguía creciendo), decía: "qué fuerte soy porque odio". Y lo grande del caso es que había algo dentro de mí que no decía nada, y yo sabía que estaba mintiendo.

Entonces, hoy sé quién soy. Hoy nadie me puede insultar. Y hoy sé qué cosa es compartir, y hoy sé que tenemos un compromiso. El compromiso empieza con uno. El que no es leal consigo mismo no puede ser leal con nadie.

Tenía siete años apenas

iQué siete años!

iNo llegaba a cinco siquiera!

De pronto unas voces en la calle

me gritaron iNegra!

¡Negra! iNegra! iNegra! iNegra! iNegra! iNegra! iNegra!

“Soy acaso negra?” -me dije

iSÍ!

“QQué cosa es ser negra?”

iNegra! 
Y yo no sabía la triste verdad que aquello escondía

iNegra!

Y me sentí negra

iNegra!

Como ellos decían

iNegra!

Y retrocedí

iNegra!

Como ellos querían

iNegra!

Y odie mis cabellos y mis labios gruesos

y mire apenada mi carne tostada

Y retrocedí

iNegra!

Y retrocedí...

¡Negra! iNegra! iNegra! iNegra!

iNegra! iNegra! iNeeegra!

¡Negra! iNegra! iNegra! iNegra!

iNegra! iNegra! iNegra! iNegra!

Y pasaba el tiempo

y siempre amargada

Seguía llevando a mi espalda

mi pesada carga

iY cómo pesaba!...

Me alacié el cabello

me polveé la cara

y entre mis entrañas siempre resonaba la misma palabra

iNegra! iNegra! iNegra! iNegra!

iNegra! iNegra! iNeeegra!

Hasta que un día que retrocedía

retrocedía y que iba a caer

iNegra! iNegra! iNegra! iNegra!

¡Negra! iNegra! iNegra! iNegra!

iNegra! iNegra! iNegra! iNegra! 
¡Negra! iNegra! iNegra!

¿Y qué?

¿Y qué?

iNegra!

Sí

iNegra!

Soy

iNegra!

Negra

iNegra!

Negra soy

iNegra!

Sí

iNegra!

Soy

iNegra!

Negra

iNegra!

Negra soy

De hoy en adelante no quiero

laciar mi cabello

No quiero

Y voy a reírme de aquellos

que por evitar -según ellos-

que por evitarnos algún sinsabor

Llaman a los negros gente de color

iY de qué color!

NEGRO

¡Y qué lindo suena! NEGRO

¡Y qué ritmo tiene!

NEGRO NEGRO NEGRO NEGRO

NEGRO NEGRO NEGRO NEGRO

NEGRO NEGRO NEGRO NEGRO

NEGRO NEGRO NEGRO 
Al fin

Al fin comprendí

AL FIN

Ya no retrocedo

AL FIN

$\mathrm{Y}$ avanzo segura

AL FIN

Avanzo y espero

AL FIN

Y bendigo al cielo porque quiso Dios

que negro azabache fuese mi color

Y ya comprendí

AL FIN

¡Ya tengo la llave!

NEGRO NEGRO NEGRO NEGRO

NEGRO NEGRO NEGRO NEGRO

NEGRO NEGRO NEGRO NEGRO

NEGRO NEGRO

iNegra soyi

\section{Poética visceral}

Toda sociedad modela una política cultural de las emociones, en la misma medida en la que se (re)configuran identidades colectivas o formas concretas de organización económica o, en sentido estricto, política: unas y otras se implican de manera multidimensional y obedecen a distintos campos de lucha. Las clases dominantes, según Bourdieu y Passeron (1995), pueden imponerse en el plano económico solo si a la vez logran hegemonizar el campo cultural y, por extensión, el campo emocional. Es claro que estos procesos obedecen a un sistema de relación de fuerzas entre los grupos y las clases, que compiten en asimetría de condiciones por la definición de un marco normativo práctico, psicológico, moral y emocional. 
Aunque no se conoce la fecha exacta en la que Victoria Santa Cruz escribe el poema "Me gritaron negra", no cabe duda de que este se inscribe en el marco histórico-ideológico del Movimiento por los Derechos Civiles y del Black Power de los años sesenta y setenta del siglo pasado, movimientos que orientaron y justificaron la lucha de las personas negras por la igualdad y la dignidad, primero en Estados Unidos y después en muchos otros lugares del mundo. El Poder Negro resalta fundamentalmente el orgullo racial afro e interpela procesos históricos coloniales de despojo, explotación, discriminación y subvaloración de las personas negras en lo que refiere no solo a bienes materiales sino también simbólicos, los cuales han dejado huella en las estructuras individuales y colectivas (Fanon, [1967] 2009).

Así como la estructura colonial se confirma y se hace performativa en signos y actos del habla, perdurando y dejando cicatrices, la deconstrucción de dicho orden incluye como elemento fundamental la palabra en forma de narrativas que desdigan dicho orden, impugnándolo desde distintos constructos y dimensiones sociales. En tal sentido, impregnada del Poder Negro, Victoria Santa Cruz apela a la indignación hecha palabra, de la misma manera que lo hicieron quienes formaron parte del Movimiento de los Derechos Civiles en muchas partes del mundo, no solo como forma de denuncia disruptiva, sino también como signo distintivo en la promoción de solidaridades entre las personas negras, insuflando a través de dicho afecto/emoción la fuerza necesaria para levantarse contra las inequidades del mundo moderno y su vector discriminatorio: el racismo.

En el caso de las mujeres negras, sus luchas han estado presentes en el campo artístico desde la segunda mitad del siglo XX. Entre los esfuerzos realizados en el arte se destaca el propósito por (re)definir las identidades negras a partir de la reconfiguración de imaginarios al margen de los 
estereotipos históricamente construidos por el orden colonial. Estas nuevas representaciones del cuerpo negro intentan desligarse del conjunto de creencias y concepciones coloniales en torno a la raza y el género, las cuales modelan la percepción de nosotros mismos y del otro, teniendo muchas veces efectos degradantes. No obstante, las producciones simbólicas de los artistas negros - tanto mujeres como hombres-, al igual que de otros subalternos, parten de una matriz cultural revitalizada a través de la cual no solo develan y actualizan lazos comunicantes, visos de identidad ancestral, sino también actualizaciones de la experiencia de las personas negras en el mundo contemporáneo.

La poesía de Victoria Santa Cruz no se encuentra en un corpus escrito sino que obedece a una profunda tradición de oralidad y expresión dancística, tanto en el continente africano como en la diáspora negra en las Américas. La presencia de los tambores que dialogan y acompañan los versos de la autora dan cuenta de lazos de unión con el pasado. El tambor, guardián de la memoria-recuerdo (Janheinz, 1963), constituye un medio de comunicación clave de la identidad negra, y responde en el poema-lírico a la fuerza histriónica y al carácter performativo de la obra de la artista peruana. Extendiendo la noción de James Scott (2000) al plano de las emociones, el lenguaje de los dununs, el repique, el bongó, los cununos, los bombos, el cajón, conlleva un "discurso oculto" en la estructura sentimental del pueblo afro en el que se transmite, entre otras cosas, una potencia disruptiva y rebelde.

En conjunto, el poema "Me gritaron negra" recuerda la dimensión visceral de las primeras etapas del feminismo, donde la rabia, la indignación y el dolor fueron modos de impugnar el orden patriarcal (Macón, 2017). En el caso de Santa Cruz, resultan ser estos mismos sentimientos la manifestación afectiva que responde radicalmente al constreñimiento subjetivo impuesto por el orden social racializado y sexista. En esta 
interseccionalidad, el orden sexista colonial-eurocéntrico asocia lo femenino con aspectos emocionales mucho más que con elementos racionales, principalmente con aquellos que modelan cuerpos y mentes frágiles, débiles y delicadas.

En el orden racializado las mujeres negras son asociadas con fuerza de trabajo, hipersexualidad y como proveedoras de "servicios para el bienestar y las necesidades reproductivas de la familia blanca-burguesa" (Zapata, 2018, p. 130). La respuesta de Santa Cruz a estas múltiples opresiones se encuentra en lo íntimo y lo emocional. Tal como lo relata en el preámbulo del poema, su propia experiencia infantil de exclusión, marginación y estigma resultó transmutada, primero en odio y luego en una posición política antirracista, mostrando su lado más radical y disruptivo.

Santa Cruz no duda en introducir las emociones al momento de presentar sus reclamos, haciendo de los afectos una dimensión relevante para la actitud y el activismo político desde la producción cultural. Al igual que lo hizo Wollstonecraft para el orden patriarcal (Macón, 2017), la autora afroperuana pretende demoler la estructura del sentir colonizador -que durante siglos buscó amilanar, acallar y hacer dóciles los cuerpos negros-, poniendo en funcionamiento el poder de los afectos en la acción políticapoética y mostrando, a partir de su propia experiencia, el papel de estos en la constitución de la subjetividad. Al igual que lo hizo la filósofa inglesa, aunque no solo ella, en el proyecto de liberación para las mujeres, Santa Cruz vehiculiza la indignación como forma legítima y efectiva de reclamar los derechos de autodeterminación de las personas negras, haciendo de ella el motor interno de cualquier proceso emancipatorio.

Tal como se señaló en el primer apartado de este artículo, la política cultural de las emociones discrimina, clasifica, diferencia, no solo entre emociones positivas/negativas, sublimes/abominables, altas/bajas, sino 
que adhiere a los cuerpos y/o las cosas sentimientos/afectos a través de las interacciones en una "economía de los afectos". El giro afectivo en su versión crítica cuestiona la diferenciación tradicional entre afectos positivos (alegría, optimismo), que se presume alientan la acción, y los negativos (vergüenza, odio, culpa), que la retienen (Tomkins, citada en Macón, 2013). Tal como afirman Lossigio y Macón (2017), se debe evitar "la asociación lineal de ciertos afectos al sometimiento y de otros a la emancipación de manera casi mágica" (p. 11). En realidad unos y otros pueden vehicular la acción o detenerla. Pueden, por ejemplo, ser instrumentalizados por políticas textuales para promover el sexismo, el racismo o la homofobia, como lo ha demostrado Ahmed (2015), o relacionarse con instancias de potencialidad emancipatoria y revolucionaria (Massumi, 2002).

Conforme a lo anterior, encontramos que la poesía de Santa Cruz tiene como anclajes emocionales movilizadores dolor, tristeza, amargura, vergüenza y odio, los cuales tradicionalmente han sido considerados negativos o dañinos; pero también apela a la indignación, la alegría y la confianza, en un proceso de transmutación que involucra, a partir de la experiencia, el descubrimiento de un cuerpo y una identidad colonizada, y después la toma de conciencia y redescubrimiento de la negridad autoafirmada.

Según Nussbaum (2008), las emociones no responden higiénicamente a la percepción del mundo, sino que involucran valoraciones, juicios y actitudes vinculados con la dimensión cognitiva, siendo irreductibles a las sensaciones corporales. Esta visión aristotélica de los afectos conduce a pensar que los sentimientos están mediados por una historia que involucra relaciones complejas en el ámbito individual y colectivo. Podemos ejemplificarlo en la historia del encuentro en el bosque entre una niña y un oso (Ahmed, 2015). Resumiendo la historia diremos que dicho encuentro 
produce la huida de la niña ante la presencia del animal. Al margen de explicaciones funcionalistas evolutivas y fisiológicas del "miedo", que darían respuestas de índole instintiva, debe considerarse en términos socio-cognitivos-emocionales. ¿Por qué le tiene miedo la niña al oso? Ahmed considera que tal miedo no reside en la bestia ni en la niña, sino en cómo entran en contacto uno y otro. Desde su enfoque se dirá que la niña tiene conocimiento (socialmente construido) sobre lo temible del animal, y que dicho conocimiento obedece a una "imagen moldeada por historias culturales y recuerdos. [...] No es que el oso sea temible 'por sí mismo'. Es temible para alguien” (Ahmed, 2015, pp. 29-30).

De la misma manera que funciona el miedo en esta historia opera la estructura del repudio hacia algo o alguien: rechazo de carácter moral orientado históricamente sobre algunos cuerpos, actos o cosas, que opera de modo inconsciente. Etimológicamente repudio tiene origen latino, repudium, que significa 'rechazo' o 'acto de rechazo', y su raíz, pudet, indica 'rechazo hacia algo que produce vergüenza'. A través de un imaginario colectivo y de una determinada forma de interacción social se organizan pública y socialmente sensaciones/emociones que a los cuerpos, en nuestro caso los cuerpos negros, en algunos contextos les han sido "pegadas" y terminan haciéndonos parecer como si emanaran directamente de ellos (Ahmed, 2015). Así como se ha adherido lo temible al oso del relato puede decirse que existen cuerpos que su superficie ha sido investida con ciertas emociones que, como el repudio y la repugnancia, delimitan espacios y marcan distancias entre unos y otros. Santa Cruz, en el preámbulo, narra el encuentro vivido en su niñez con la niña "gringa" y el inmediato rechazo de ella a "jugar" junto con el cuerpo negro de Victoria. Ella fue repudiada por la caucásica, quien seguramente había aprendido a sentir vergüenza de compartir con Otro al que no consideraba digno de establecer con ella relaciones de cercanía (física, 
moral, simbólica). Es así como se ejemplifica la capacidad de las emociones para delimitar espacios/distancias, cercanías/lejanías, lo que determina quiénes pertenecen y quiénes quedan fuera del espacio social (Ahmed, 2015), así como a quiénes se permite formar parte de ciertos círculos de confianza.

Con el acto de repudio, la sensación de vergüenza se instala en el cuerpo de la niña negra, que descubre lo que significa ser negro a través de los afectos, en el marco de una economía de las emociones en un mundo hegemonizado por la supuesta supremacía blanca. Son tan evidentes las redes de poder extendidas en el episodio vivido por Santa Cruz, y tan fuerte la estructura afectiva que lo precede, que sus propias amigas mestizas optan por decirle que se retire, lo que le causa así un profundo dolor en la estima de la niña, un dolor que se manifiesta como "una puñalada”. Ahora bien, no se debe entender el proceder de sus compañeras de juego como un acto esencialmente discriminatorio, sino como una conducta de subordinación a una política cultural de los afectos, que implica una compleja red de relaciones de poder.

El dolor es irreductible a la simple sensación, pues conlleva la atribución de significado a través de la experiencia. Además, no es solo un efecto del daño que ha experimentado el cuerpo, sino que "es crucial en la formación del cuerpo como una entidad tanto material como vivida" (Ahmed, 2015, p. 52). A través de la experiencia de dolor Santa Cruz llega a sentir su piel negra como una superficie corpórea que, en esa situación, la separa de las otras. El sentimiento vivido es tanto interno como externo: una "puñalada" en la superficie, una herida profunda en la estructura interna del yo. Es posible decir que la experiencia de dolor fuera vivida por la futura artista como una vuelta a una nueva forma de conciencia de sí. Dicha experiencia, dada la intensificación de las sensaciones, dejará una impresión 
imborrable en la superficie de su cuerpo (su piel negra) y significará un punto de quiebre en la formación del carácter y de su propia identidad. Con la experiencia de dolor Santa Cruz reconoce los límites corporales, así como la impresión/herida con la cual ha sido investida a partir de dicha experiencia. Según Wendy Brown (citada en Ahmed, 2015), en muchas ocasiones la herida ocupa el lugar de la identidad misma, y entra en conflicto con la necesidad de dejar ir los investimientos de dolor. Dicho conflicto lo describe Santa Cruz en el poema como una "pesada carga" que se manifiesta, primero, en la interiorización del dolor y en una postura natural de aversión, transmutada en odio sobre los otros, universales blancos; segundo, en una imagen confusa de su propia identidad que nos recuerda las palabras de Fanon ([1967] 2009) en cuanto a la distorsión efectuada por el imperialismo blanco sobre las identidades negras, que no muestran límites claros entre el sí mismo y el otro.

Los sentimientos de amargura y dolor llevan a Santa Cruz a "retroceder" frente a aquellos (otros) que imponen el orden moral y racial, obligándola a trastocar la percepción de ella sobre sí misma, lo que la hace querer modificar su superficie corpórea "alisándose" el cabello, "polveándose" el rostro, negando su propia identidad racial. De tal forma, este blanqueamiento de piel y el alisamiento de cabello vienen marcados por la hegemonía estética occidentalocéntrica, y tiene repercusiones importantes en la creación de las subjetividades y en las múltiples identidades de la mujer negra.

La marca afectiva que provocó vergüenza en su infancia y distorsión en sus propios códigos identitarios, así como un odio movilizador hacia sí misma y hacia los otros, trasmutó en "orgullo" tanto en la vida como en el poema de Santa Cruz, en un clima emocional de época plagado de tensiones raciales, movido a su vez por el sentimiento de esperanza que acompañaba la rebeldía de los subordinados. Si el orden social racializado y su régimen 
de sentimentalidad le habían hecho retroceder, la reafirmación de la identidad negra (“iNegra! Ś́”) y el reconocimiento de su superficie corpórea (“iNegra soy!”) -investida ahora de sentimientos de confianza, amor y alegría - , le permiten la reconciliación, avanzando sin miedo en el camino que procura hacer efectivo el ideario de libertad y dignidad para las personas afro.

\section{Conclusiones}

Los feminismos negros tienen su génesis en el contexto norteamericano de la segunda mitad del siglo XIX, pero adquieren visibilidad y potencia en el marco de la lucha por los derechos civiles en los Estados Unidos de los años sesenta del siglo pasado. Así mismo, se debe destacar en este proceso el papel de las intelectuales inglesas de la escuela de Birmingham en la segunda mitad del siglo XX, desde el enfoque de la nueva izquierda y bajo presupuestos de la perspectiva poscolonial. En Suramérica la artista afroperuana Victoria Santa Cruz cuenta entre las pioneras de la movilización organizada en defensa de los derechos y la vindicación de las personas negras. Desde el ámbito cultural hizo derroche no solo de calidad artística sino también de activismo político en defensa de los pueblos afroamericanos, promoviendo procesos emancipatorios y solidaridades desde la autoafirmación y reconfiguración de las identidades negras.

La vida y obra de Santa Cruz encarna la vocación por derruir lo que persiste de la estructura colonial y su orden social racializado, apelando a los afectos y las emociones como instrumentos para hacer efectivos sus reclamos. Desde la puesta en escena su sentir político-poético tiene el tono visceral y auténtico tanto del incipiente movimiento feminista de finales del siglo XVIII como de las luchas por los derechos civiles de las personas negras en Norteamérica de mediados del siglo XX. A partir del análisis de su experiencia hecha poema es posible inducir el papel de los

Hallazgos

ISSN: 1794-3841 | e-ISSN: 2422-409X | DOI: https://doi.org/10.15332/2422409X

Vol. 18 N.0 36| julio-diciembre del 2021 
afectos/emociones en el reconocimiento de las superficies corpóreas, en la delimitación de distancias y espacios sociales y en la producción de subjetividades.

Interacciones de la vida cotidiana como las que Santa Cruz experimentó en su infancia dan cuenta de los efectos de la economía cultural de las emociones en la manera como los sujetos se reconocen a sí mismos y reconocen a los otros en contextos socioculturales interétnicos. De este modo se establecen jerarquías afectivas que se adhieren a los cuerpos y pueden servir como justificantes de la desigualdad, la discriminación y la exclusión.

El proceso vivido por Santa Cruz muestra el debate posmoderno en torno a las identidades y subjetividades, lo que permite entender que la identidad no es una característica estática y unitaria (Ang-Lygate, 2012). Las identidades son complejas, diferenciadas y obedecen a dinámicas de las relaciones sociales como un constructo a través del espacio y el tiempo, a partir de una historia casi siempre opuesta a otras identidades.

Adelantándose a su época, la poesía de Santa Cruz se acerca a las formulaciones de la tercera ola feminista en cuanto a poner de relieve el papel de los afectos en la constitución de la identidad/subjetividad, en cuyo proceso no hay mucho espacio para la razón. Su producción cultural no escamotea el sentimiento de indignación ante las injusticias históricas sobre el pueblo afro; por el contrario, cada una de sus letras y su capacidad histriónica potencializan dicho afecto, elevándolo a categoría emancipatoria en la gestación de solidaridades.

Por otro lado, la autora trasmuta las emociones en palabras, lo que da cuenta de la manera en que entran en juego y son parte integral del ser humano en el proceso de (re)conocimiento de su corporeidad y la de los 
otros, coadyuvando en la definición de códigos identitarios que pueden alinearse con una política cultural hegemónica o resistirse a esta.

\section{Sobre el autor}

Juan Carlos Zuluaga Díaz. Sociólogo de la Universidad del Valle, Colombia. Especialista en Políticas Culturales, Universidad de Barcelona. Magíster en Investigación en Ciencias Sociales, Universidad de Buenos Aires. Profesor del Departamento de Antropología y Sociología de la Universidad de Caldas, Colombia, donde actualmente es director del programa de Sociología. Áreas de interés: estudios culturales/salud; relaciones interraciales; representaciones sociales; movilidad social. Entre sus publicaciones más recientes, están los artículos académicos:

"Disfunción sexual femenina y promoción de la enfermedad: aproximación desde el análisis crítico del discurso" (2020); "El campo cultural y el mundo de las letras en Occidente: formación y desarrollo" (2020); "Pautas normativas y formas de racionalidad en la movilidad social afrodescendiente en Tuluá, Colombia" (2020); "Medicalización, promoción de la enfermedad y disfunción sexual femenina” (2018); “iLe cayó mosca a la leche!: discriminación racial y movilidad social en Tuluá" (2015); "Afrodescendientes, representaciones y movilidad social en Tuluá" (2015), y una reseña "Tejidos mediáticos de lo negro. Hacia una topografía racializada de la nación colombiana, de Catalina Zapata Cortés" (2020).

\section{Referencias}

Ahmed, S. (2015). La política cultural de las emociones. Universidad Nacional de México. Ang-Lygate, M. (2012). Trazar los espacios de la deslocalización. De la teorización a la diáspora. En M. Jabardo (Ed.), Feminismos negros. Una antología. (pp. 291-314). Traficantes de Sueños. 
Bourdieu, P. y Passeron, J. C. (1995). La reproducción: elementos para una teoría del sistema de enseñanza. Distribuciones Fontamara.

Butler, J. (2002). Cuerpos que importan: sobre los límites materiales y discursivos del "sexo". Paidós.

Cvetkovich, A. (2012). Deppresion: A public feeling. Duke University Press.

Fanon, F. (2009). Piel negra, máscaras blancas. Akal. (Trabajo original publicado en 1967).

Flatley, J. (2008). Affective mapping: Melancholia and the politics of Modernism. Harvard University Press.

Gamba, S. (2008). Feminismo: historia y corrientes. Diccionario de estudios de género y feminismos. Biblos.

González, G. (2018). Los feminismos afro en Latinoamérica y el Caribe, tradiciones disidentes: del pensamiento anticolonial a la defensa de la tierra. Revista Investigaciones Feministas, 9(2), 239-254. https://doi.org/10.5209/INFE.58936

Gordillo, S. K. (2020). "Me gritaron negra”: entre la negación y la reivindicación. Foro: Revista de Derecho, (33), 143-174. https://doi.org/10.32719/26312484.2020.33.8

Hooks, B. (2004). Mujeres negras. Dar forma a la teoría feminista. Otras inapropiables (pp. 33-50). Traficantes de Sueños.

Illouz, E. (2007). Intimidades congeladas. Las emociones en el capitalismo. Katz.

Ingenio Comunicaciones. (2008, junio 29). Victoria Santa Cruz: Me gritaron negra. [Archivo de video]. YouTube. https://www.youtube.com/watch?v=754QnDUWamk

Jabardo, M. (Ed.) (2012). Feminismos negros: una antología. Traficantes de Sueños. Janheinz, J. (1963). Muntu: las culturas neoafricanas. Fondo de Cultura Económica. Lossigio, D. y Macón, C. (Eds.) (2017). Afectos políticos: ensayos sobre actualidad. Miño y Dávila Editores.

Macón, C. (2017). Ansiedad, indignación y felicidad para la emancipación: el camino de Mary Wollstonecraft. En D. Lossigio y C. Macón (Eds.), Afectos políticos: ensayos sobre actualidad (pp. 31-50). Miño y Dávila Editores. 
Macón, C. (2013). Sentimus Ergo Sumus. El surgimiento del "giro afectivo" y su impacto sobre la filosofía política. Revista Latinoamericana de Filosofía Política, 2(6), 132.

Macón, C. y Solana, M. (Eds.) (2015). Pretérito indefinido: afectos y emociones en las aproximaciones al pasado. Recursos Editoriales.

Maiarú, J. (2018). Me gritaron "negra”, Negra soy: interpelación y agencia discursiva en la construcción de la identidad. III Congreso Internacional de Identidades. Centro Interdisciplinario de Investigaciones de Género.

http://sedici.unlp.edu.ar/handle/10915/96002

Massumi, B. (2002). Parables for the virtual: Movement, affect, sensation. Duke University Press.

Mouffe, C. (2016). Política y pasiones: el papel de los afectos en la perspectiva agonista. Universidad de Valparaíso.

Nieto, M. (2019). Protofeminismo negro, orgullo racial y reconfiguración de la mujer afrolatinoamericana en las voces literarias de Nancy Morejón y Victoria Santa Cruz. Pontificia Universidad Católica de Valparaíso. http://opac.pucv.cl/pucv txt/txt-9500/UCC9741 01.pdf

Nussbaum, M. (2008). Paisajes del pensamiento: la inteligencia de las emociones. Paidós.

Pujadas, J. (2002). El método biográfico. El uso de las historias de vida en ciencias sociales. Cuadernos Metodológicos (5). Universidad Complutense de Madrid.

Restrepo, E. (2003). Racismo y discriminación racial. Instituto de Estudios Sociales y Culturales PENSAR.

Scott, J. (2000). Los dominados y el arte de la resistencia: discursos ocultos. Ediciones Era.

Victoria Santa Cruz. (6 de abril). Wikipedia, La enciclopedia libre. https://es.wikipedia.org/w/index.php?title=Victoria_Santa_Cruz\&oldid=1345675 07

Young, I. M. (2000). La justicia y la política de la diferencia. Cátedra.

Zapata, C. (2018). Tejidos mediáticos de lo negro. Hacia una topografía racializada de la nación colombiana. Pontificia Universidad Javeriana.

Hallazgos

ISSN: 1794-3841 | e-ISSN: 2422-409X | DOI: https://doi.org/10.15332/2422409X

Vol. 18 N.o 36| julio-diciembre del 2021 
Zuluaga, J. C. (2015). iLe cayó mosca a la leche!: discriminación racial y movilidad social en Tuluá. Revista de Antropología y Sociología: Virajes, 17(1), 305-333.

http://virajes.ucaldas.edu.co/downloads/Virajes17(1) 14.pdf

Hallazgos

ISSN: 1794-3841 | e-ISSN: 2422-409X | DOI: https://doi.org/10.15332/2422409X

Vol. 18 N.o 36| julio-diciembre del 2021 